\title{
DIMENSÕES DE UM CAMPO MUSICAL LOCAL E SUAS RELAÇÕES COM A EDUCAÇÃO MUSICAL: RESULTADOS DE UM PROGRAMA DE FORMAÇÃO DE PROFESSORES'
}

Jusamara Souza

\section{Resumo}

Este artigo tem como foco a experiência de um programa de formação de professores realizada no âmbito do Edital PROEXT. O Programa combinou cursos de formação musical, produção de material didático e uma investigação de cunho sociográfico-musical. A pesquisa teve como objetivo analisar a inserção de práticas musicais na comunidade e suas relações com a educação musical. As dimensões sociomusicais, socioprofissionais e socioeducativas presentes nas práticas musicais locais podem contribuir para se pensar a música na escola.

\section{Palavras-chave:}

Educação Musical; Sociologia da Música; Campo Local; Formação de Professores

A implementação da Lei Federal 11.769/ 2008 que dispõe sobre a obrigatoriedade do ensino da música na educação básica trouxe grandes desafios para as escolas e para os sistemas de ensino no Brasil. Uma questão a enfrentar é o tratamento da música nas escolas como um conteúdo que deverá ser garantido em todas as séries. Para os professores das séries iniciais do ensino fundamental, essa situação torna-se ainda mais difícil visto que são poucos os que possuem uma formação específica ou preparo suficiente para contemplarem as atividades musicais na sua prática.

Na maioria das vezes, o conteúdo da aula de música é desvinculado do meio sociocultural em que alunos e professores vivem. Além disso, diversos pesquisadores da área de educação musical vêm questionando a presença reduzida da música na escola, quando as diversas manifestações musicais estão tão presentes na vida cotidiana contemporânea (Hentschke e Oliveira, 2000; Souza,

\section{Abstract}

This article focuses on the experience of a teacher training program conducted under the Edital PROEXT, which includes musical training courses, production of teaching material and sociographic research in music. This study aims to analyze the insertion of musical practices in the community and their relationship with music education. Socio-musical, professional and educational dimensions in local musical practices can contribute to thinking of music within the school.

\section{Keywords:}

Music Education; Sociology of Music; Local Field; Teacher Training

2000; Penna, 2002). Acredito também que a experiência pedagógica musical não pode desconhecer a referência cultural presente na comunidade local, pois a escola é uma instituição acentuada pelas relações entre escola e cultura presentes em todo processo educativo.

Certamente, muito já se fez para a efetivação da música na escola. Depois de vários debates e audiências públicas, em dezembro de 2013, tivemos a elaboração de Diretrizes Nacionais e sua aprovação pelo Conselho Nacional de Educação (CNE) como mais uma ferramenta para promover uma real implantação da música na escola. Como a literatura da área revela nos últimos anos vários movimentos exigiram um compromisso nacional para que uma política de estado para que a educação musical escolar fosse implantada. No nível regional e local, foram implementadas diversas ações e propostas, incluindo desde a abertura 
de concursos públicos para professores de música; investimentos na infraestrutura e instalações necessárias para a implementação da música nas escolas; investimentos em compras e manutenção de instrumentos musicais, equipamentos e materiais didáticos; fomento de grupos vocais e/ou instrumentais de diferentes estilos e formações; investimentos na formação continuada de professores para atuar com música nas escolas; até a formação de professores (ver documentos GT, Souza et al. 2010).

Este artigo apresenta algumas reflexões sobre as culturas musicais locais e suas relações com a educação musical, destacando as dimensões sociomusicais e socioeducativas. Trata-se de uma experiência realizada no município de Salvador do Sul, uma pequena cidade localizada no interior do Rio Grande do Sul, na qual buscamos ${ }^{2}$ integrar a pesquisa - no formato de uma sociografia musical feita na comunidade - com a formação de professores.

\section{Sobre as ações para a formação de profes- sores}

Em2010 concorremos ao Editaln ${ }^{\circ}$ 05-PROEX/2010 - SESu/ MEC e fomos contemplados com o Programa "Música, Cotidiano e Educação". Através desse Programa, e com os recursos do Edital, foram desenvolvidos cursos de formação continuada para professores da rede pública de quatro regiões do país, nas cidades de Marabá (PA), Duas Estradas $(P B)$, Uberlândia (MG); Jussara e Santa Fé (PR); Salvador do Sul e Gramado (RS). A formação continuada foi destinada a professores de todos os níveis da educação básica contemplando mais de 500 professores.

O Programa foi executado pelo Grupo de Estudos e Pesquisa Educação Musical e Cotidiano vinculado ao Programa de Pós-Graduação em Música da Universidade Federal do Rio Grande do Sul (UFRGS) e ao Diretório de Pesquisa do CNPq, coordenado por mim desde 1996. O Grupo tem como objetivo analisar a música e suas relações com a educação, na perspectiva das teorias do cotidiano.

Além das nossas discussões e pesquisas em torno dessa temática, temos desenvolvido regularmente projetos de extensão. Com esses projetos não só defendemos a ideia de que os problemas de pes- quisas em educação musical devem ser oriundos da prática e a ela retornar (Bastian, 1997), como também temos reforçado o papel social da pesquisa e seu compromisso com a formação de professores. Por esta razão, há muito faz parte das nossas tarefas regulares, como grupo, a promoção de cursos que visem à formação de professores para trabalhar com música nas escolas, diante da demanda que a Lei 11.769/2008 criou.

Ao propormos ações que visem à formação de professores apoiamos nos pressupostos de que: 1) os educadores são produtores de saberes sobre o ensino-aprendizagem, e, portanto, podem e devem participar ativamente dos rumos de sua formação; 2) um programa de formação continuada deve estar integrado com as políticas municipais de educação para que haja diálogo entre as diferentes instâncias e continuidade das propostas; 3 ) devem ser criadas condições efetivas, em cada escola, para o debate e promoção de espaços para a construção coletiva de saberes; e 4) devem ser consolidados espaços para discussões teórico -práticas, utilizando-se de suportes tecnológicos como blogs e sites que permitam a interação entre os educadores participantes do programa e a comunidade.

Acreditamos, também, que o sucesso da formação continuada de professores em serviço deve se ancorar no esforço colaborativo do desenvolvimento de propostas, em que as demandas concretas dos municípios - expressas pelos professores, diretores, alunos, pais e dirigentes - orientem o trabalho. Ao pensarmos nas diferentes etapas de um mesmo programa, pensamos que é possível superar um modelo de formação continuada de professores concebida de forma homogênea, fragmentada e descontínua.

Além dos cursos de formação continuada para professores, oferecidos para as redes de ensino público e privado, o Programa previu a elaboração de material didático com a produção digital de um DVD e a publicação de uma coleção ${ }^{3}$ com cinco livros, com referências curriculares e propostas de atividades a serem desenvolvidas nos diferentes níveis da educação básica (infantil, fundamental e médio) e educação de jovens e adultos, como material de apoio didático.

Outra ação do Programa foi a articulação de uma rede nacional com instituições de ensino superior 
para criar um banco de dados e de espaços para a divulgação e publicização das ações implementadas divulgadas pelo site www.ufrgs.br/musicanaescola. Conhecer e analisar os dados sobre a rede onde os professores em formação atuam bem como conhecer as demandas das Secretarias Municipais de Educação e a realidade local de cada município permitiram estruturar uma ação educacional mais orgânica e efetiva.

Dos resultados deste Programa pode-se destacar a articulação institucional entre a UFRGS e as universidades parceiras, bem como com as prefeituras municipais que se comprometeram com a formação continuada para a implementação da lei 11.769/2008 nas redes de ensino. A experiência realizada em Salvador do Sul ${ }^{1}$ pode exemplificar essa continuidade.

\section{A experiência em Salvador do Sul}

Uma das demandas das prefeituras envolvidas e dos professores participantes foi a continuidade dos cursos de formação, incluindo uma formação teórica consistente da abordagem da música como uma prática social vinculada as culturas musicais locais e uma integração maior da escola com a cultura presente nos municípios. Para tanto, propusemos junto com a formação de professores no município de Salvador do Sul ${ }^{4}$, localizado no interior do Rio Grande do Sul, a realização de uma pesquisa que abrangesse as práticas musicais da cidade.

Ao longo de 2011 e 2012, fizemos um mapeamento e diagnóstico de equipamentos culturais e práticas na educação musical, com o objetivo de identificar as atividades musicais desenvolvidas, analisar as relações entre elas e a inserção destas práticas na comunidade, bem como discutir suas potencialidades para a educação musical, analisando como a música na escola poderia dialogar com a vitalidade cultural (cultural vitality) da comunidade na qual está inserida.

Os pressupostos teóricos das pesquisas e ações de extensão que vimos empreendendo ancoramse na perspectiva sociocultural da educação musical que tem como argumento central de que práticas musicais são experiências sociais. Apoiada em autores da sociologia da música (Bozon, 2000; DeNora, 2000; Green, 2000) que reco- nhecem a constituição social e cultural da música como "uma particular e irredutível forma de expressão e conhecimentos humanos" os projetos partem de uma visão cultural da música proposto por Shepherd e Wicke (1997). Nessa concepção, a performance musical, está associada ao "fazer musical" e ao "senso de musicalidade" das pessoas como fruto da interação interpessoal (Small, 1977). O processo de ensino e aprendizagem de música e conduzido pela "ação de fazer música" ou "musicando" (musicking) (Small, 1995), incorporando os processos coletivos intersubjetivos e dialógicos. A performance musical, nessa perspectiva, abrange "os rituais", "os jogos", "o entretenimento popular" e as formas de interação as quais são entendidas como espaços de ensino e aprendizagem musical.

Examinar a cultura musical local sob esse enfoque permite uma abordagem da música não como um objeto, mas como uma experiência social, incluindo a sensibilidade emocional, os ambientes onde as pessoas vivem, trabalham, a circulação de seus capitais simbólicos (Bourdieu, 2000). A música como "um fenômeno transversal que perpassa a sociedade" (Bozon, 2000) apresenta-se em uma comunidade local de uma maneira singular, mas dotada de valores e crenças que resultam na identidade cultural do município.

Qual é a importância deste tema? A sociedade contemporânea vem passando por mudanças significativas que se refletem na visão de cultura, escola, processo de ensino e aprendizagem, desafiando a construção de caminhos no cotidiano escolar que deem conta da diversidade. O olhar para a vitalidade cultural evidencia a criação, difusão, validação, legitimação e apoio às artes e à cultura como uma dimensão da vida cotidiana (Matarazzo, 1999; Jackson, 2008).

\section{Como foi feita a pesquisa?}

A presença da música no cotidiano de uma cidade pode ser captada de várias formas. Na pesquisa realizada em Salvador do Sul, optamos por realizar uma sociografia musical, inspirados no trabalho de Bozon (2000). Em sua pesquisa, Bozon descreve e analisa práticas de grupos musicais presentes em uma pequena cidade operária na região de Lyon, França, procurando "extrair as 
características gerais do campo local que as constituem" (p. 148). As atividades musicais selecionadas emergiram como um campo privilegiado para se observar as diferenças entre os grupos sociais. Para Bozon (2000), a prática musical é um "fenômeno transversal, que perpassa toda a sociedade" e que "constitui um dos domínios onde as diferenças sociais ordenam-se da maneira mais clássica e marcante, mesmo se os agentes sociais, mais seguido e constantemente que em outros campos se recusem a admitir que a hierarquia interna da prática é uma hierarquia social" (p. 147). O autor, apoiado na noção de campo social de Pierre Bourdieu, conclui: “longe de ser uma atividade unificadora no que concerne todos os ambientes sociais e todas as classes, a música é o lugar por excelência da diferenciação pelo desconhecimento mútuo; o gosto e os estilos seguidamente se ignoram, se menosprezam, se julgam, se copiam" (p. 147).

Escolhemos a cidade de Salvador do Sul como campo empírico em função de algumas particularidades. Diferente de outras cidades do interior brasileiro, em que a maioria dos municípios não conta com nenhum tipo de equipamento cultural, nem com políticas públicas na área de música, o município tem um movimento artístico-musical intenso, com diversos corais, bandas escolares, bandas de rock, outros grupos instrumentais, inclusive mantendo uma escola municipal para o ensino de artes. Pode-se fazer menção, aqui, à Oficina Municipal de Artes de Salvador do Sul (OMA) que disponibiliza gratuitamente mais de 20 oficinas à comunidade, entre as modalidades de música, dança, teatro, esportes e ginástica.

A cidade pertence a uma região em que há numerosos coros de tradição germânica, justamente fruto dessa colonização alemã. Portanto, a presença de muitas atividades musicais pode ser explicada, em parte, pela relação dos descendentes de imigrantes alemães com a música, especialmente na tradição de coros, sejam eles vinculados à igreja ou não.

O fio condutor da pesquisa aqui apresentada é a concepção de práticas musicais como práticas sociais apoiada na sociologia da música. Entender a música como prática social significa compreender que as exigências técnico-musicais estão ligadas às práticas de sociabilidade nos grupos, na família, na escola, na igreja e na comunidade. Como escreve Anne Marie Green (2000), a música é um objeto complexo por se tratar de um fato social total que coloca em jogo e combina aspectos técnicos, sociais, culturais e econômicos. A partir dessa perspectiva "que busca ter uma visão do conjunto das relações que se tecem, isto é, entendendo a música como uma realidade social com seus múltiplos aspectos" (GREEN, 2000, p. 34), a autora acredita que podemos ter uma compreensão mais aguda, mais sensível e mais larga dos fatos musicais. Esse entendimento mais ampliado, sobre o significado social da música, é útil para compreender as diferentes práticas musicais dos diversos grupos de estudantes na escola ou em outros espaços.

Além disso, para o campo pedagógico musical, esta perspectiva pode também revelar a constituição de diferentes grupos e suas escolhas musicais e como isso se apresenta na aula de música. Dessa forma, como já discutido em outros textos (Souza, 2004), o que estaria no centro da aula de música seriam as relações que os alunos constroem com a música, seja ela qual for. Por isso, é mais importante definir o tipo de relação que os alunos mantêm com a música do que "se limitar a um estudo da prática ou do consumo musical unicamente por seu conteúdo ou gênero de música apreciada ou escutada" (GREEN, 1987, p. 95).

Através do estudo sobre a diversidade das práticas musicais encontradas em Salvador do Sul, destacando-se a variedade dessas práticas vividas pelos músicos amadores e profissionais, buscou-se responder a dois objetivos específicos: a) elaborar um "mapa" que pudesse mostrar a pluralidade de atividades musicais e os mecanismos de diferenciação, aproximações e tensões discutidos por Bozon (2000); b) refletir sobre as condições de permanência, ou de declínio, de determinadas práticas musicais, com o objetivo geral de vincular esses conhecimentos com a educação musical, especialmente aquela que se faz na escola.

A sociografia musical como instrumento de coleta e análise combinou abordagens qualitativas e quantitativas, utilizando entrevistas individuais e coletivas bem como questionários ${ }^{5}$. 0 design metodológico adotado foi inspirado nos estudos sociográficos musicais de Monteiro (2009; 2011) e Guerra (2011).

A pesquisa foi realizada no período de novembro a maio de 2012, com diferentes atividades. Além da 
participação direta da equipe da UFRGS, a pesquisa contou com o apoio da Prefeitura quanto ao suporte logístico, em termos de pessoal e material. A investigação foi desenvolvida em quatro etapas: fase de planejamento, fase da coleta de informações, fase de análise dos dados e fase da divulgação dos resultados. Na fase de planejamento, foram definidas as ações adequadas à realidade do município, um trabalho conjunto da equipe de pesquisa com os gestores da Prefeitura de Salvador do Sul. Com essa articulação foi possível identificar o público informante ser consultado, os critérios de escolha e seleção dos músicos participantes e estratégias metodológicas para a obtenção de dados.

Através de contatos pessoais ou por telefone, foram selecionados, como participantes, músicos, bandas e grupos representativos da comunidade. As entrevistas individuais foram realizadas enfocando o histórico de determinadas práticas, escolares e não escolares, com a música na comunidade; trajetórias de vida profissional e musical; modos de aprendizagem de música e grau de investimento na música.

Foram entrevistadas pessoas pertencentes a nove grupos de músicos selecionados para participarem desta pesquisa. Esses grupos musicais são: Orquestra Jovem (16 participantes), Coral Bom Progresso (20 participantes), Coral Concórdia (19 participantes), Coral Municipal de Salvador do Sul (25 participantes), Quarteto da Fumaça (4 participantes), Happy Brass (10 participantes), Banda Blue Label (5 participantes), Banda Viva Alegre ( 9 participantes), Banda da Escola Estadual de Ensino Médio São Salvador (25 participantes). Além desses grupos, pudemos contar com o depoimento de músicos praticantes de diferentes gêneros: Ademir Holderbaun e mais três de seus familiares, Charles Wentz e Padre Pedro Norberto Link.

O roteiro utilizado para as entrevistas foi estruturado a partir de quatro eixos: identidade (quem são os músicos), alteridade (como se veem e são vistos), interação (como convivem com outros músicos na comunidade) e educação musical (o que pensam da música na educação). Esse roteiro permitiu explorar distintas visões, estilos e temporalidades presentes na vida musical da cidade. Além disso, o roteiro incluiu o relato de momentos vividos e de contato com a música ao longo da vida (infância, adolescência, juventude e vida adulta); agentes/instâncias de socialização (amigos, irmãos, pais, tios, professores) e experiências marcantes (concertos, festivais, saídas, viagens, entre outras).

O contato com os músicos locais e a realização dos encontros que impulsionaram o mapeamento deu visibilidade ao projeto junto às comunidades local e regional. Um dos resultados da pesquisa foi a produção do documentário ${ }^{6}$ intitulado $D i$ versidade nas Práticas Musicais: um olhar para a vitalidade cultural na comunidade de Salvador do Sul/RS. Com a duração de 35 minutos, o filme faz um registro da música na cidade, com recortes das entrevistas dos grupos e músicos que participam das manifestações culturais na região. 0 vídeo contribuiu para a interação, a troca de conhecimentos e a circulação de informações sobre os músicos residentes no município.

A seguir, são apresentadas análises de dados derivados das entrevistas qualitativas que foram realizadas e cujos trechos estão disponíveis no documentário.

\section{Dimensão sociomusical: Trajetórias e práti- cas musicais}

O caráter qualitativo das entrevistas permitiu que as distintas visões, estilos e temporalidades presentes na vida musical da cidade, assim como experiências e vivencias marcantes (individuais e comunitárias em relação à música), pudessem ser captadas através do relato desses participantes.

No roteiro de entrevistas foram considerados aspectos como marcos biográfico e suas relações com as atividades musicais desenvolvidas e estilos musicais preferidos. Nas muitas histórias de vida coletadas, surgiram relatos de como aprenderam música, a participação da família, a transmissão da música pelas gerações, a presença da música nas escolas.

A importância da música na estruturação da identidade e no modo de vida dos entrevistados pode ser vista nos vários depoimentos. A identidade do indivíduo vai sendo construída por meio das relações socioculturais estabelecidas com a família, os amigos e a escola, a mídia e as instituições religiosas o que vai tornando-o consciente de sua singularidade. Um dos músicos da banda Happy 
Brass conta:

Eu comecei na música com 8 anos. Na minha família parente nenhum era músico. Até hoje a gente não sabe direito porque eu tive esse gosto musical. Mas, a partir dos 8 anos, que um dia eu vi um folhetozinho de uma loja lá, um teclado, eu me apaixonei, assim, foi à primeira vista e daí eu pedi, bah, pai, eu quero esse teclado. E o pai, aquela vez, ele fez de tudo, tudo o que podia para comprar, as condições não eram assim tão boas, mas ele conseguiu comprar [o instrumento]. Talvez por esse esforço também, vendo ele fazer esse esforço por mim, é um gosto tão grande, que eu iniciei nessa parte da música.(Músico da Happy Brass)

Já outro músico da Banda Viva Alegre, revela:

\begin{abstract}
[...] o que me levou a aprender música aos 35 anos foi que desde criança meu sonho era ser músico. Então tinha um rádio a pilha, a gente escutava as bandinhas, aí a gente ia pra roça arrumar pastos pros animais e assoviava a música, porque eu queria música! (Músico da Banda Viva Alegre)
\end{abstract}

As relações sociais estabelecidas com a música é um dos temas examinados pela sociologia da música quando procuramos entender melhor o comportamento das pessoas em relação à música considerando os efeitos das instituições: a família, a escola, a mídia, a religião. A convivência com a família, com os grupos, nos momentos de sociabilidade auxilia no processo de aprendizagem musical. O músico Ademir Holderbaun conta que viveu "vinte anos aproximadamente, trabalhando na roça, depois também com acácia, produção de carvão." Seu depoimento contem exemplos de processos de aprendizagem musical que são incorporados da família. Aprendizagens que são individuais, porém mediadas pela presença do pai que tocava e pelas experiências com música feitas na comunidade:

O pai já tocava um pouquinho algum instrumento, tocava gaita, umas e outras músicas, à noite [..]. Depois do serviço, ele ficava tocando e eu era pequeno,ficava apreciando, depois quando às vezes aparecia umas festas, mesmo que raramente a gente podia ir junto, toda vez que tinha uma festa, músico tocando, eu ficava observando. Mesmo não tendo música tocando, ficava olhando só os instrumentos. Aí, o pai, depois quando cresci um pouco, foi incentivando para eu aprender a tocar e com 13, 14 anos consegui um professor no interior[...].Ademir Holderbaun

Vinculado à questão dos descendentes de imigrantes alemães e identidade com a música, o relato do Padre Pedro Norberto Link revela parte da herança cultural alemã na educação musical escolar, construída no Colégio Santo Inácio, que funcionou de 1937 a 1990 e atendeu mais de 3.000 alunos:

No começo era português, aritmética, geografia, história, música...era teoria e também a prática e chegamos a formar uma orquestra aqui. Eu não me lembro quantas figuras eram, mas enchiam mais ou menos uma sala assim... Eu me lembro de um canto Alleluia, de Haendel, era cantado no dormitório, na Páscoa. Então, isso era... aquilo enchia de fato o coração. Eu fui destacado para trabalhar aqui como mestre, como professor e para cuidar do grupo de alunos. Aí eu comecei a juntar dinheirinho pra comprar uma dúzia de gaitinhas e uma dúzia de flautas. Eu entreguei o dinheiro para um padre alemão que daqui ia para a Alemanha e lá, na Alemanha, havia dois estudantes jesuítas. Então, eu pedi para ele entregar o dinheiro, comprar as gaitinhas e mandá-las depois pra cá. Chegamos a tocar pros benfeitores de Montenegro 7. Acho que alugamos uma Kombi pra colocar a turminha e fomos, passamos o dia lá, tocando pra rapaziada, foi um dia de folga e deram muita alegria pros benfeitores ( $\mathrm{Pa}$ dre Pedro Norberto Link).

O depoimento revela como os imigrantes alemães trataram de movimentar o campo da música na educação e o legado desse movimento para a comunidade. Como escreve Bozon, "a originalidade do campo musical está no fato de que, cobrindo um espaço social muito extenso ele permite a observação simultânea de continuidades e de descontinuidades, (...)" (BOZON, 2000, p.172).

\section{Dimensão socioprofissional}

As entrevistas realizadas com os grupos musicais em um número total de nove, e com os três músicos individuais, como mencionado, permitiram identificar os componentes e descrever as práticas musicais típicas de cada grupo. Além disso, os dados coletados permitem analisar como os músicos se tornaram profissionais, que grupos constituíram, que investimentos fizeram, como e com que frequência se apresentam e como convivem com outros músicos na comunidade.

Um ponto de encontro dos músicos entrevistados é a Festa do Turismo - Festur, organizada anualmente pela Prefeitura Municipal de Salvador do Sul. O evento promove apresentações e shows musicais de grupos e bandas locais, regionais e nacionais consagradas pelo público.

As atividades musicais promovidas na Festur revelam aspectos das políticas culturais para o município nos quais está presente o dilema da tradição, 
da conservação para que a herança cultural não desapareça, mas que abarque o novo, as novas gerações. A Festur torna-se um lugar de encontro das múltiplas pertenças identitárias como a Banda Happy Brass "que leva adiante os costumes e a tradição germânica do município" e a Banda de rock Blue Label que, segundo seus participantes, causa um certo estranhamento numa cidade pequena.

Guardiões da memória musical coletiva, os músicos dizem possuir objetivos comuns em prol do desenvolvimento cultural da cidade baseado nos princípios de cooperação, convivência, na "amizade entre os músicos" já que tocar juntos "são reencontros", e que outros grupos são mais "amigos que concorrentes, tudo é necessário" (Ademir Holderbaun).

Sobretudo, os músicos estão atentos às heranças: "eu toco na Banda dos Bravos", uma referência na letra de uma das músicas da Blue Label a uma banda na qual seus pais tocavam: "O Charles [Wentz] fazia parte da banda dos nossos pais." Segundo Charles Wentz, em seu depoimento, os integrantes da Blue Label são "filhos de músicos cujos pais tinham o Grupo dos Bravos, junto conosco, e a Blue Label é uma banda que toca música nos 70 , e toca 2012. É uma banda de excelente qualidade."

\section{Dimensão socioeducativa}

A sistematização da área de educação musical com o seu corpus de conhecimentos e resultados permite afirmar que "a prática pedagógicomusical encontra-se em vários lugares, ou seja, os espaços onde se aprende e ensina música são múltiplos e vão além das instituições escolares" (Souza, 2007, p.28). Considerando que a educação musical se ocupa "com as relações entre pessoa(s) e música(s) sob os aspectos de apropriação e transmissão" (Kraemer, 2000, p.65), o desafio tem sido, então, fazer o diálogo entre as diferentes formas de apropriação e transmissão do conhecimento musical produzidos socialmente. Para a educação musical escolar isto significa estar atento às formas de ensinar e aprender música que são feitas no mundo cotidiano vivido (SOUZA, 2008).

Nesse processo, a educação musical promovida nas escolas vem sendo entendida como uma pos- sibilidade de "ampliar o alcance e a qualidade da experiência musical do aluno". O trabalho pedagógico-musical na escola deve "tomar a vivência do aluno como ponto de partida para, reconhecendo como significativa a diversidade de manifestações musicais [...] (Penna, 2002, p.18).

Incluir a música na escola significa exercer o direito da música para todos sem distinção de condições socioeconômicas, sociais e culturais, de gênero, condição étnico-racial ou necessidades especiais. É respeitar a noção de música (arte) que está expressa na Constituição Federal de 1988 e na Lei de Diretrizes e Bases da Educação Nacional (Lei no 9.394/1996).

Como parte integrante do currículo escolar a música requer a construção de concepções e práticas plurais, mantendo as diferentes culturas e tradições presentes nas diferentes regiões do país. 0 papel da música na escola em todos os níveis e modalidades do ensino deve incluir as possibilidades de profissionalização na área e seus possíveis processos de aplicação no mundo do trabalho. Também há que se considerar o papel da música na educação integral e no projeto ampliado de escola que exige a cooperação com outras instituições e sujeitos de comunidade como, por exemplo, mestres da cultura popular e oficineiros.

A música fornece ferramentas que permitem aos cidadãos conhecer e se relacionar com as produções culturais e simbólicas do passado, e com aquelas produções do presente, através de sua recepção e produção Como escreve Arroyo (2002), "as práticas musicais compreendem um complexo de aspectos, desde os produtores e receptores das ações musicais, o que eles produzem, como e porque, e todo o contexto social e cultural que dá sentido às próprias ações musicais" (p.29). Assim, pode-se afirmar sobre a importância desse processo para a formação de grupos e sociabilidade, como também para o respeito pela diversidade de identidades e o refinamento de uma sensibilidade multicultural. Dessa forma, se utilizada dentro de preceitos éticos e de defesa dos direitos humanos, a cultura musical de uma cidade torna-se, portanto, vital para o exercício da democracia. Essa dimensão do fenômeno musical é também sublinhada por Bozon (2000), visto que a música desempenha "um papel importante no 'vivido" pelos praticantes: seu caráter social devido ao fato de que a prática em si implica em relações entre as pessoas que tocam juntas, e induz, ao mesmo 
tempo, a um processo de diferenciação entre grupos de música" (p. 147-148).

Na pesquisa realizada em Salvador do Sul, vários depoimentos afirmaram a importância de se incluir a música na educação e como ela pode fazer parte de um currículo escolar. A prática coral na comunidade tem um papel fundamental e configura-se como um espaço de sociabilidade e de encontro.

\section{Considerações finais}

No artigo foram discutidas questões relacionadas à música e educação musical, recuperando-se a vitalidade cultural de uma cidade através das experiências e histórias vividas pelos entrevistados. A relação das pessoas com a música e seus efeitos no cotidiano de Salvador do Sul- momentos, grupos, espaços - é muito significativa e, por isso, a relevância de estudar esse campo local de uma perspectiva compreensiva e como um fato social, investigado "a partir da experiência vivida por um grupo social sabendo-se que essa sociedade é o resultado das condutas musicais de atores singulares em relações que ligam uns aos outros» (GREEN, 2000, p.34).

Para Green, o objetivo é não sacrificar os aspectos teóricos do fato social em geral, nem os aspectos específicos do musical, que se encontram além do social, e sim conseguir colocar em evidência as suas interdependências. Como diz a autora, devese saber «estudar a música como uma realidade social com seus aspectos múltiplos, levando-se em conta que essas camadas se interpenetram» (GREEN, 2000, p.34). O modelo interpretativo de Green anuncia "uma visão global da música, sem perder de vista os aspectos sociais e humanos", uma vez que a prática musical é fruto da realidade humana. Segundo Green,

não existe objeto musical independentemente de sua constituição por um sujeito. Não existe, portanto, por um lado, o mundo das obras musicais (que não são entidades universais e se desenvolvem em condições particulares ligadas a uma dada ordem cultural), e por outro, indivíduos com disposições adquiridas ou condutas musicais influenciadas pelas normas da sociedade. A música é, portanto, um fato cultural inscrito em uma sociedade dada [...]. (GREEN, 1987, p. 91; Tradução nossa).

Isso significa compreender que a música está li- gada a outras esferas da vida - amigos, profissão, lazer, subjetividades, família... - e, por isso, a sua importância também na educação escolar. A inserção da prática musical na escola dependerá de circunstâncias que variam com os interesses locais, com a realidade cultural e social de cada aluno e aluna.

Em fevereiro de 2013 trabalhamos em conjunto com Prefeitura Municipal de Salvador do Sul um curso de Formação continuada para professores da Rede Municipal de Salvador do Sul e região com o objetivo de qualificá-los para o trabalho na escola a partir de uma visão sociocultural de currículo. O mapeamento de equipamentos culturais e práticas na educação musical registrado no documentário Diversidade nas Práticas Musicais serviu como mote para repensar a relação entre escola,cultura e comunidade.

\section{Notas}

1. Este artigo amplia algumas das reflexões feitas durante o I Colóquio de Pesquisa em Educação Musical realizado pelo Programa de Pós-Graduação em Artes do Instituto de Ciências da Arte da Universidade Federal do Pará (UFPA), realizado de 24 a 26 de junho de 2014, em Belém. O tema proposto para o evento foi "Trânsito entre fronteiras na educação musical".

2. A equipe de pesquisadores compreendeu Jusamara Souza (Coordenação geral), Renita Klüsener (UFRGS), Matheus de Carvalho Leite (Mestrando/ UFRGS) e Ana Claudia Specht (Doutoranda/ UFRGS). O curso de formação de professores foi coordenado por Jusamara Souza e Ana Cláudia Specht.

3. Esta Coleção pertence à Série "Educação Musical e Cotidiano", coordenada por Jusamara Souza e publicada pela Tomo Editorial de Porto Alegre. Nesta série já foram publicados três livros: a) em 2011, "Música na Escola -Propostas para a implementação da lei 11.769/08 na Rede de Ensino de Gramado, RS", organizado por Jusamara Souza; b) em 2013, “Educação musical, cotidiano e ensino superior" organizado por Ana Lúcia Louro e Jusamara Souza; c) em 2014, "Música, Educação e Projetos Sociais", de Jusamara Souza e outros. Compõem ainda esta Série "Educação Musical e Cotidiano", os outros dois livros que têm previsão 
de publicação para 2014, com os títulos/temas: "Pesquisa Qualitativa em Educação Musical"; e "Temas para o ensino de música na escola".

4. A cidade de Salvador do Sul possui aproximadamente 7.000 habitantes, em sua maioria constituída de descendentes de alemães. 0 território faz parte do Vale do Caí, localizado na Serra Gaúcha.

5. Neste artigo serão contempladas apenas informações coletadas durante as entrevistas.

6. Como já informado anteriormente, a produção do documentário é parte integrante do Programa Música Cotidiano e Educação - Proext 2010, contando com a parceria institucional da UFRGS e Prefeitura de Salvador do Sul/RS. A produção do vídeo foi realizada por uma empresa especializada e contou com o apoio do Programa de Pós Graduação em Música/UFRGS e do Grupo de Pesquisa Educação Musical e Cotidiano (CNPq//UFRGS), e com financiamento do MEC/SESU.

7. Salvador do Sul foi emancipado de Montenegro em 9 de outubro de 1963, através da Lei Estadual $n^{\circ} 4.577$ e posterior alteração no artigo $2^{\circ}$.

\section{Referências}

ARROYO, M. Educação musical na contemporaneidade. Anais do II Seminário Nacional de Pesquisa em Música da UFG. Goiânia, p.18-29, 2002.

BASTIAN, Hans Günther. (Empirische) Forschung in der Musikpädagogik im Fokus pragmatischer methodologie. In: PFEFFER, M. et al. (Org.): Systematische Musikpädagogik. Augsburg: Wissner, 1997. p. 205-228.

BOURDIEU, P. Cuestiones de sociologia. Tradução Enrique Martín Criado. Madrid: Istmo, 2000.

BOZON, M.. Práticas musicais e classes sociais: estrutura de um campo local. Em Pauta, v. 11, n. 16/17, p. 146-174, abr-nov, 2000.

DENORA, T. Music in everyday life. Cambridge: Cambridge University Press, 2000.

GREEN, A. M. Les comportements musicaux des adolescentes. Inharmoniques "Musiques, Identités", v. 2, p. 88-102, Mai 1987.

GREEN, A. M. Lesenjeux méthodologiques d 'une approche sociologique de faits musicaux.In: A. M. GREEN (Org.). Musique et sociologie: enjeux méthodologiques et approches empiriques. $\mathrm{Pa}$ ris: L'Harmattan, 2000, p. 17-40.

\section{Pesquisa em sociologia da educação} musical. Revista da ABEM, Salvador, n. 4, p. 2535, 1997.

GUERRA. P. Culturas Urbanas e Modos de Vida Juvenis: Cenários, sonoridades e estéticas na contemporaneidade portuguesa (2005-2009) Tese de Doutorado (Sociologia). Instituto de Sociologia da Faculdade de Letras da Universidade do Porto Departamento de Sociologia da Faculdade de Letras da Universidade do Porto, 2011.

HENTSCHKE, L.; OLIVEIRA, A. A educação musical no Brasil. In: HENTSCHKE, Liane (Org.). A educação musical em países de línguas neolatinas. Porto Alegre: Ed. Universitária/UFRGS, 2000. p. 47-64.

JACKSON, M. R. Medindo a vitalidade cultural em comunidades, 2008.

KRAEMER, R. -D. Dimensões e funções do conhecimento pedagógico-musical. Trad. Jusamara Souza. Em Pauta, v. 11, n. 16/17, p. 49-73, abr-nov. 2000.

MATARAZZO, F. Medindo Índices de uma Cultura Local - Medindo a vitalidade cultural das comunidades, 1999.

MONTEIRO, C. A. Campo musical Cabo-Verdiano na área metropolitana de Lisboa: Protagonistas, Identidades e Música Migrante. Tese Doutorado (Sociologia) ISCTE-Insituto Universitário de Lisboa, 2009, 397p.

C. A. Música Migrante em Lisboa. Trajectos e Práticas de Músicos Cabo-Verdianos. Lisboa: Editora Mundos Sociais, 2011.

PENNA, M. Professores de música nas escolas públicas de ensino fundamental e médio: uma ausência significativa. Revista da Abem, Porto Alegre, n. 7, p. 7-19, set 2002.

SMALL, C. 1977. Music, society, education. Hanover: University Press of New England.

C. 1995. Musicking: A ritual in social space. http://www.musikids.org/musicking.html. 24 Janeiro 2006. 
SOUZA, J. Educação Musical e Cotidiano: Algumas Considerações. In: Souza, Jusamara. (Org.). Música, Cotidiano e Educação. Porto Alegre: CORAG, 2000, p. 150-165.

J. Educação musical e práticas sociais.

Revista da ABEM, v.10, p. 7-11, 2004.

J. Pensar a educação musical como ci-

ência: a participação da Abem na construção da

área. Revista da Abem, Porto Alegre. n. 16, p. 25-

30, mar. 2007.

J. et al. Audiência Pública sobre políti-

cas de implantação da Lei Federal n¹1.769/08

na Assembleia legislativa do Estado do Rio

Grande do Sul. Revista da Abem, Porto Alegre. n.23, p.84-94, mar. 2010. (Documentos).

SOUZA, J. (Org.) Aprender e ensinar música no

cotidiano. Sulina: Porto Alegre, 2008.

\section{Sobre a autora}

Jusamara Souza possui graduação em Instrumento - Piano pela Universidade Federal de Uberlândia (1979), Licenciatura em Música e Artes pela Universidade de Bremen - Alemanha (1988), Mestrado em Educação Musical pela Universidade de Bremen - (1988) e Doutorado em Educação Musical e pela Universidade de Bremen - Alemanha (1993). Atualmente, é Professora Associada do Programa de Pós-Graduação em Música da Universidade Federal do Rio Grande do Sul. Foi presidente da Associação Brasileira de Educação Musical nos períodos de 2001-2003 e 2003-2005. De 2002 a 2008, foi diretora da Editora da UFRGS. É pesquisadora do CNPq e desde 1996 coordena o Grupo de Pesquisa Educação Musical e Cotidiano (UFRGS/CNPq). Tem experiência na área de Música, atuando principalmente nos seguintes temas: educação musical, aprendizagem e ensino de música no cotidiano, sociologia da educação musical. 